\title{
The waiting time paradox: population based retrospective study of treatment delay and survival of women with endometrial cancer in Scotland
}

\author{
Simon C Crawford, Jonathan A Davis, Nadeem A Siddiqui, Linda de Caestecker, Charles R Gillis, \\ David Hole
}

Department of Gynaecological Oncology, Stobhill Hospital, Glasgow G21 3UW

Simon C Crawford specialist registrar Jonathan A Davis consultant

Nadeem A Siddiqui consultant

Department of

Public Health,

Greater Glasgow

Health Board,

Glasgow G3 8YT

Linda de

Caestecker

consultant

West of Scotland

Cancer Surveillance

Unit, Department of

Public Health,

University of

Glasgow, Glasgow

G12 8RZ

Charles R Gillis

professor

David Hole

professor

Scottish

Programme for

Clinical

Effectiveness in

Reproductive

Health, Aberdeen

Maternity Hospital,

Aberdeen

AB25 2ZL

Gillian Penney

programme

coordinator

Correspondence to:

S C Crawford

S.C.Crawford@

btinternet.com

BMJ 2002;325:196

Delay in the delivery of treatment for gynaecological cancers has been previously investigated. ${ }^{12}$ In some cases, the delay reflects the illness behaviour of women; in others, it was inherent in the system for delivering health care. Few studies have linked delay in treatment with survival, although a study from Israel found that survival from endometrial cancer was not affected by a delay in treatment of four months. ${ }^{3}$

We investigated links between delays in treatment and survival, using a recently completed audit of endometrial cancer treatment in Scotland.

\section{Methods and results}

We collected data from the case notes of all women resident in Scotland who were diagnosed between 1 January 1996 and 31 December 1997 as having endometrial carcinoma. Of 781 cases, we found case notes for 714, and, out of these, we analysed the 703 cases that involved operative treatment.

We calculated time intervals from the dates of general practitioner referral letters, clinic appointments, investigations, and operations. We allocated an International Federation of Gynaecology and Obstetrics (FIGO) stage to each case retrospectively ${ }^{4}$; we then categorised cases by FIGO stage. ${ }^{5}$ We linked these data to survival information from ISD-Scotland and did a univariate analysis using the Kaplan-Meier method and multivariate analysis using Cox's proportional hazards analysis.

Delay and survival were inversely related: women with the shortest delay had more advanced disease and survival was least likely for these patients (table). This trend is seen most starkly in the delay from general practitioner referral to first hospital visit.

Interval from general practitioner referral to surgery and survival

\begin{tabular}{|c|c|c|c|}
\hline & & Hazard & $5 \%$ Cl) \\
\hline & No & Univariate analysis & Multivariate analysis \\
\hline GP to surgery interval: & & & \\
\hline$<40$ days & 154 & 1 & 1 \\
\hline 40-61 days & 155 & 0.50 (0.30 to 0.82$)$ & 0.71 (0.43 to 1.19$)$ \\
\hline 62-91 days & 155 & 0.34 (0.19 to 0.59 ) & $0.47(0.27$ to 0.83$)$ \\
\hline$>92$ days & 153 & $0.39(0.23$ to 0.67$)$ & $0.53(0.30$ to 0.93$)$ \\
\hline Age: & & & \\
\hline$<60$ years & 135 & 1 & 1 \\
\hline$\geqslant 60$ years & 545 & 1.83 (1.06 to 3.16$)$ & 1.28 (0.72 to 2.30 ) \\
\hline FIGO stage category: & & & \\
\hline 1AG1 and 1BG1 (low risk) & 182 & 1 & 1 \\
\hline $\begin{array}{l}\text { 1AG2/3, 1BG2/3, and 1CG1/2 } \\
\text { (intermediate risk) }\end{array}$ & 289 & 3.11 (1.38 to 7.01$)$ & $2.8(1.15$ to 6.85$)$ \\
\hline 1CG3, stages 2/3/4 (high risk) & 182 & 12.8 (5.9 to 27.9 ) & 11.1 (4.74 to 25.8 ) \\
\hline Cannot be assigned to case & 50 & 5.8 (2.2 to 15.2$)$ & 5.2 (1.85 to 14.7$)$ \\
\hline Adjuvant radiotherapy: & & & \\
\hline Yes & 275 & 1 & 1 \\
\hline No & 428 & 0.83 (0.57 to 1.19 ) & 2.00 (1.29 to 3.11$)$ \\
\hline
\end{tabular}

The median interval from referral to definitive operation was 62 days (90th centile 150 days). Large variations between health board areas existed: the median interval from referral to definitive operation varied from 46 to 81 days (74 to 287 days).

\section{Comment}

The interaction between survival and delay in treatment is complex: we found that patients who experience the longest delay in treatment are more likely to survive. This is paradoxical: it is popularly assumed that delay has a significant and harmful impact on survival.

This interaction is partially accounted for by the relation between stage and delay but is only partly explained by the FIGO stage category in a Cox proportional hazards model corrected for age, stage, and use of radiotherapy.

The traditional view is that delay caused by organisational defects has an adverse effect on the disease: this influences survival. Our study suggests that disease influences delay, and so delay is a confounding factor.

The fact that the strongest effect between delay and survival is seen in the interval between referral and the first hospital visit suggests that general practitioners communicate information related to presentation in some way to consultants. This communication ensures that consultants respond faster to patients who are at higher risk. Consultants seem to be able, from first clinic visit, to differentiate patients at greater risk and to ensure that cancer is diagnosed and treated faster. Women with the longest delays have the best survival, and vice versa, suggesting that the "healing art" remains an important but elusive factor.

We acknowledge the Information and Statistics Division, Edinburgh, for cancer registration and survival data. Medical case note abstraction was by Edith Hamilton and Sheena Mitchell.

Contributors: All members of the study group were involved in the design and implementation of the study. SC and LdC wrote the paper and all authors contributed to its revision. SC is guarantor.

Funding: Greater Glasgow Health Board endowment fund. Competing interests: None declared.

1 NHS Executive. Guidance on commissioning cancer services: improving outcomes in gynaecological cancers: the research evidence. Wetherby: Department of Health, 1999:25-6. (Catalogue no 16149.)

2 Fruchter RG, Boyce J. Delays in diagnosis and stage of disease in gynaecologic cancer. Cancer Detect Prev 1981;4:481-6.

3 Menczer J, Krissi H, Chetrit A, Gaylor J, Lerner L, Ben-Baruch G, et al. The effect of diagnosis and treatment delay on prognostic factors and survival in endometrial carcinoma. Am J Obstet Gynecol 1995;173:774-8.

4 Shepherd JH. Revised FIGO stages for gynaecological cancer. Br J Obstet Gynaecol 1989;96:889-92.

5 Creutzberg CL, van Putten WL, Koper PC, Lybeert ML, Jobsen JJ, Warlam-Rodenhuis CC, et al. Surgery and postoperative radiotherapy versus surgery alone for patients with stage-1 endometrial carcinoma: multicentre randomised trial. PORTEC Study Group. Post Operative Radiation Therapy in Endometrial Carcinoma. Lancet 2000;355:1404-11. (Accepted 12 December 2001) 